\title{
A Qualitative Narrative Study of English Preparedness among Recent Graduates of a Taiwanese Private University
}

\author{
Jeff Luther \\ Chung Hua University \\ Taiwan
}

\begin{abstract}
This qualitative narrative analysis examines the experiences of four recent college graduates from an English program at a private Taiwanese university. Their stories also allow us to assess the success or failure of their program of study in a way that is not possible simply by examining graduation rates and employment statistics.
\end{abstract}

Keywords: qualitative, narrative analysis, Taiwanese, ESL, Higher Education,

\section{1: Introduction}

When I took a job in a university in Taiwan six years ago, I found myself at the US consulate attending to some visa issues. The embassy clerk made small talk, remarked that my Taiwanese visa was being sponsored by a university, and asked me very casually "Is it a real university or a diploma mill?". I had heard that pejorative term before used to mean a university that operates like an assembly line, admitting almost everyone and graduating almost everyone regardless of learning outcomes. The question, unfortunately, is not without legitimate merit. To understand why educational outcomes are under such pressure, we have to understand something of the changes in the Taiwanese higher education system over the last few decades.

Between 1986 and 2006, the number of universities in Taiwan increased from 105 to $163-$ - a 55\% increase over only twenty years. Enrollment at each of these universities also increased resulting in a 197\% increase in the number of undergraduate students by the 1990s. The vast majority of these students, 74\%, attend private universities (Chen and Chang, 2010, p. 1).

Having three fourths of undergraduate students enrolled in private universities is noteworthy for a number of reasons. Public universities in Taiwan receive substantial government support which has resulted in their developing the best facilities, recruiting the most accomplished faculty members, having the best reputations, and by far the lowest tuition and fees. Competition is fierce for high school graduates to get a coveted place in a public university. Private universities are left to fight for all the rest.

And recruitment is a fight and becoming more so yearly. At the same time a rapid expansion of universities was occurring, a population drop was beginning. The population decline began slowly twenty years ago, gradually declining and then more rapidly. There are no signs the trend will reverse, and Taiwan now has the world's lowest birthrate with an average of precisely 1.0 child per woman of childbearing age (Tso, 2009, p. 2 ). The ramifications for the education system are obvious. However, universities will experience this drop off of potential students long after the effects have been seen in elementary schools and kindergartens giving them the benefit of having longer to prepare.

According Taiwan's Ministry of Education (MOE) enrollment data, in the 2002- 2003 school year kindergartens enrolled 240,000 students. In the 2008-2009 school year, they enrolled only 185,000. The loss of 55,000 students over the course of just six years resulted in the elimination of 3,085 full-time teaching jobs-- a stunning loss of 1.4 teachers per day, every day, for six years (MOE, 2011, p. 1).

The inevitable result is too few students to support the number and size of existing universities. This in-turn sets up a set of logical repercussions. Universities must either close or lay-off faculty members if they cannot recruit sufficient students. Thus, there is powerful pressures at work to admit gradually weaker and weaker students who are less well prepared to succeed in college. If students are forced to complete a series of remedial courses, recruiting these students becomes more difficult because of the extra cost and time they would be expected to invest in their education. 
This results in downward pressure on learning outcomes and course goals as they become increasingly difficult or impossible to meet as students are arriving with a weaker foundation of skills and study habits. A university department that is failing half its students can not survive because it cannot retain them. The trend, fueled by unalterable economic and demographic realities, seems unavoidable: downward pressure, lower standards, nearly a $100 \%$ graduation rate, and remain economically solvent.

English departments remain particularly vulnerable to this downward pressure for a number of reasons. Students majoring in English typically arrive in college with a significant level of English proficiency. Entrance interviews are often conducted exclusively or primarily in English, and application packets have bilingual components. One is not necessarily expected to have some basic knowledge of designing a home to major in architecture, for example, but would be required to already have made significant progress toward English proficiency before beginning such a program. As a result, the curriculum is designed with this level of proficiency in mind. The curriculum is likely to begin with some classes taught exclusively in English with most of the others having a significant portion of their content in English making the curriculum very sensitive to drops in beginning student proficiency levels. English acquisition for adults also tends to be slow but gradual. Thus, as the average proficiency level of incoming students decreases, the average English proficiency level of graduates shows a corresponding decrease.

It would be easy to vilify the private university system for devolving into diploma mills, and graduating students with diplomas that may or may not be worth much and who may or may not be adequately prepared for professional challenges in the real world. In another sense this situation may be the inevitable outcome of an economic and demographic reality that is out of their control.

But what becomes of these students after they graduate? Given the scope of the question, I am interested in examining a specific subsection of college graduates: those who have majored in English as a foreign language. Majoring in English is generally considered an economically viable end unto itself in Taiwan even without necessarily preparing one for a specific career role. This becomes especially pertinent given the above mentioned downward pressure affecting standards.

\subsection{Problem Statement}

That a college education in English is preparing students for the world by helping them acquire a level of proficiency sufficient to find employment in a field using said proficiency is both an implied and stated goal of English departments in Taiwanese universities. The extent to which private universities are able to fulfill this promise is being gradually weakened by seemingly inexorable economic and demographic forces. The extent of this weakening is not fully understood, and there is additionally a severe lack of understanding concerning the effect that this weakening has on the lives of those people directly affected by it.

\subsection{Purpose of the Study}

The purpose of this narrative study, which involves collecting stories from four graduates, majoring in English at a private Taiwanese university, is to understand the extent to which these graduates were prepared to meet the professional challenges of life after college. Through their stories, this qualitative narrative study will add a greater depth of understanding to the broader ramifications of this situation by examining what happens to these students after college. In this way it will add a new level of understanding that demographic details and unemployment rates cannot do alone.

\subsection{Central Question}

The central question and supporting questions will seek to better understand post graduation professional experiences of students who have graduated from private Taiwanese universities in the last three years. Our central question and sub questions further seek to understand how well students were prepared to meet professional challenges after graduation. The central question thus becomes: How well were recent graduates of private Taiwanese universities, who have majored in English, prepared to meet the professional challenges they faced after college.

\subsubsection{Sub questions}

The following sub questions are addressed in this study:

1. To what extent did participants feel they were prepared for a professional life after graduating from college?

2. What role does a graduate's proficiency play in their job? 
3. How did the participant's English fluency influence their ability to meet their professional goals after graduation.

\subsection{Delimitations}

This study is limited to college graduates who graduated from private universities in Taiwan in the past three years and majored in English. The study is further limited to those willing to share their stories.

\subsection{Limitations}

Because Taiwan has a system of compulsory military service for males beginning shortly after college graduation and lasting one-year, there is an added complexity in their availability to the study and an effective one-year delay in their professional experiences which may decrease the likelihood of their choosing to participate in this study. As a qualitative narrative study, it is not possible to generalize these findings to other graduates, departments, or universities in Taiwan.

\subsection{Significance of the Study}

Through their stories, this qualitative narrative study will add a greater depth of understanding to the broader ramifications of what professional challenges students face after graduation and how well they are prepared to meet them. Through this greater understanding, the strengths of their college program of study can be identified and expanded and the deficiencies identified and remedied.

\section{Methodology}

This is a qualitative narrative study. A narrative approach "begins with the experiences as expressed in lived and told stories of individuals" (Creswell, 2007, p. 54). Through these stories, a greater level of understanding can be reached in appreciating the professional challenges these adults faced after graduating from college, and we may likewise come to see the extent to which their university curriculum has prepared them or failed to prepare them for these challenges-- all from the perspective of the people who lived these experiences. It is important to capture this perspective because it adds a human dimension to a situation that might instead be represented by only distant unemployment statistics.

\subsection{Central Question}

The central question and supporting questions seek to better understand post graduation professional experiences of students who have graduated from private Taiwanese universities in the last three years. Our central question and sub questions further seek to understand how well students were prepared to meet professional challenges after graduation. This study is thus guided by the following central question: How well were recent graduates of private Taiwanese universities, who have majored in English, prepared to meet the professional challenges they faced after college?

\subsection{Sub questions}

1. To what extent did participants feel they were prepared for professional life after graduating from college?

2. What role does a graduate's proficiency play in their job?

3. How did the participant's English fluency influence their ability to meet their professional goals after graduation.

\subsection{Participants}

Participants are adults who have graduated from a private Taiwanese university within the last three years and who majored in English. The following participants meet the study criteria and have agreed to participate in the project. All participants were traditional college students (attended college directly from high school) and are thus in their early 20s:

Participant A Female, 1 year since college graduation

Participant B Female, 1 year since college graduation

Participant $\mathrm{C} \quad$ Female, 2 years since college graduation

Participant D Female, 1 year since college graduation

\section{Results and Analysis}

The central question that guided this study was an investigation into how well recent graduates of private Taiwanese universities, who have majored in English, were prepared to meet the professional challenges they faced after college. 
The four interviews conducted collectively suggested an enlightening story with many common themes. All interviews were conducted in a private conversation lounge at Chung Hua University in Hsinchu, Taiwan. Participants individually all selected this interview location. The first interview was recorded with digital video and a redundant audio recording. The remaining interviews were recorded with a primary and secondary audio format. One interview was transcribed while the other three audio files were reviewed as necessary. Notes were taken during the interview process as well.

All interviews were conducted in English. All participants were second language learners of varying degrees of proficiency. As such, during the interview process, questions were occasionally restated or simplified as necessary. Additional questions were asked to follow-up on emerging themes or ask for clarification. All participants were assigned the following non-identifying pseudonyms for the purposes of the narrative analysis:

Participant A: Ann Female, 1 year since college graduation

Participant B: Matilda Female, 1 year since college graduation

Participant C Christie Female, 2 years since college graduation

Participant D Wendy Female, 1 year since college graduation

\subsection{Narrative Analysis}

Ann was the third person I interviewed, and as such I had already begun to notice some common themes emerging. I was already curious to see if these themes would continue to develop or if her story would move in a new direction. As it turns out, Ann's story was in some ways prototypical of the stories I heard while still being completely unique.

Ann had graduated from college the previous spring, so she had been out of school for approximately fourteen months. I could tell that she was a little nervous when she arrived, but she also seemed really eager to share.

Ann's story started off, as many stories do, with a trip and an adventure. Ann, along with a friend, went to Alaska for four months to participate in a "working vacation" program that gives young people the chance to live in the United States, experience the country and culture while working to support them.

"So what did you do while you were there", I inquired.

"Laundry" she answered matter-of-factly. "in a fish product place, so I needed to wash their gloves". If it seems odd that one's first job out of college is doing laundry at a fish processing plant in a foreign country, you would have missed the first common theme in the stories. The goal after graduation is improving English and preparing for other, future opportunities rather than starting a career.

This was an idea offered by Matilda as well: "I want to study abroad next year. I want to improve my English and get my masters in something. I'm not sure what yet. I'm not sure where I want to go". In fact, all participants planned to study abroad in the future--even the ones who had already been abroad. In one case it was in a couple of months, in two other cases the plan was "next year" and in the final case the plan was "when I can afford it". Interestingly, no participants had any concrete plans for going abroad if their purpose was to study. No one had been accepted to or even applied to a program. "going abroad" was an end unto itself rather than a means to an end. Even the one participant, preparing for a year long working vacation program in Canada, had no idea what job she would do once there and had only a vague geographic destination. The goal was the experience itself and improving one's English. As Ann said, "after four years of study, everyone wants to go abroad to improve their English ability".

When Ann returned from Alaska, she described a second common theme. Asked about employment she described working as a receptionist but concluded, "I don't like that job because it's kind of a little boring" in summarizing why she left after three months. Matilda too shared a similar experience. A teacher refereed her to an English language school for a teaching position. Matilda told me "I didn't prepare at all for the interview because I didn't want to get the job. I just, I wasn't sure what I wanted to do". The prospective employers liked her, she told me, but thought she had done poorly on the interview, so they called the teacher who had recommended her. "Are you sure about Matilda. Are you sure she can do this?" Matilda related to me. "So my teacher told them I was probably just nervous or scared and told them I would be great. So they offered me the job. I decided to take it because it was my teacher's reputation on the line". She went on to conclude that she needed the experience, and it would give her the chance to save money to study abroad next year. The goal of gaining experience and saving money was also specifically expressed by Wendy in nearly identical language as she said "I have to stay for a year because I signed a contract. 
It's ok cause I need the experience and to save the money. After that though I want to go to improve my English abroad. I might go to research school." (graduate school).

Christie reported a similar experience. She described her time since college in chunks of jobs she didn't like and the time between them. Both of the jobs were in department stores: "I'm into fashion, so I think it will be an interesting job. Actually, it's not" she concluded about her first job selling shoes at a department store. Again though working was described as a means to an end: "I want to study in America or Canada. Or maybe New Zealand, I am not sure" she concluded, and the jobs were a means to save money toward that end.

Another theme emerged in the types of jobs. Of the four participants, two worked in teaching children in private English language schools. Both referred to the job as something they were doing to save money but did not plan to do long term. However, both participants had or planned to stay for at least one year, had not quit, and had not quit or held a different job before or after.

The remaining two participants, Ann and Christie, worked in service-oriented jobs. Both participants in the service sector had held two jobs in the past year with a period of unemployment between them. Of these four jobs, hotel receptionist, waitress, and sales clerk at a department store, sales clerk at a different department store, only the position as a hotel receptionist required a significant amount of English, but even here Ann said, "you don't need to be talented in English, but you have to have the ability to talk with customers".

In getting her first job Ann said she had never taken a proficiency test as part of the interview process, but she "the interview was half in English and half in Chinese". Three participants had attended interviews conducted at least half in English. Both participants who took jobs in English language schools said they had done poorly in an English interview. However, both participants eventually got a job where they did poorly. Wendy said, "They told be I made a lot of mistakes with my verbs, my past tense verbs, and they were worried whether I can teach kids or not. But they gave me another chance and asked me to come back and interview again ten days later". Matlida, as already noted, did poorly enough on an interview for the employer to question her references as to her suitability, but strongly suggested she intentionally underperformed because she wasn't sure if she wanted the job or not.

A final theme that emerged was in response to the question about the curriculum of the English program they graduated from. All four students mentioned the English oral communication portion of the curriculum. While it may be expected that participants would cite those classes with the most direct practical application as opposed to, say, linguistics or literature, it is still somewhat curious that not a single person mentioned their writing classes.

\section{Reflection and Conclusions}

The first sub question investigated participants' perceptions of their own preparedness to meet professional challenges after graduating from college. Findings indicated that all four subjects indicated a desire to study and/or live abroad in order to improve their English. This was not necessarily connected to an intention to complete further education such as graduate school. When further studies were indicated, they were identified only as broad goals without a specific location or even a program of study. However, improving English was always given as a goal. This suggests participants did not feel that their English ability was adequate to meet long-term professional goals.

All four participants stressed the temporary nature of their jobs. This is to be expected to a certain extent from anyone in their early 20s, but two of the participants had held, quit, and held again service level jobs where neither English nor even a college education are a prerequisite. Both participants used the words "boring" to describe these jobs. While the participants either didn't seek or did not find more challenging employment is unclear this may indicate lack of preparation to meet professional challenges, but this could be due to lack of ambition, lack of proficiency that would grant the opportunity, or lack of confidence.

The second sub question investigated the role a graduates' proficiency played in their job. The results indicated that two participants use English extensively at work because they teach English at private language schools. One participant uses no English at work at all, and the remaining participant left one job requiring basic English while her second job required only incidental use of English. We can conclude that for those participants who worked as teachers, English proficiency plays a significant role in their jobs because they use it every day with both students and native speaking English teachers. For the remaining two participants, their proficiency level is unimportant because there is no significant English use at work. 
The final sub question examined how the participant's English fluency influenced their ability to meet their professional goals after graduation. Results indicated that the participants had no professional goals in terms of career. Participants specifically articulated a desire to not be in their current jobs long term without being able to articulate a long term career goal. However, all participants indicated a desire to improve their English further by studying or living abroad. This offers two possible interpretations. The first is that the high development of their English proficiency enabled them to go abroad to learn and that second is that a low development of their English proficiency required them to go abroad to improve it further after college. The correct interpretation is that both are true. While the first is a prerequisite to learning abroad, the second is clearly the motivating factor. This is supported by the fact that participants all collectively expressed the same desire: to study abroad, while collectively expressing the same limiting lack of a goal beyond improving English proficiency. We can thus conclude that participants felt that their English proficiency needed to improve further after graduation.

The central question asked how well recent graduates of private Taiwanese universities, who have majored in English, were prepared to meet the professional challenges they faced after college. By the participants' own assessment, the answer is that they lacked the proficiency level they felt they needed. This is demonstrated in that they all individually expressed the need to study English abroad to increase their proficiency level. If we disregard their self-assessment, the facts suggest a more complex, split conclusion. The two participants who are working as language teachers have faced no professional challenges they were unable to overcome. However, the results for the other two participants are more complex as they have effectively faced no professional challenges related to English proficiency levels, and perhaps this absence of challenges is itself an indictment on their preparedness.

\subsection{Recommendations}

Findings suggest a split may be present among recent graduates that results in radically different levels of ability to meet professional challenges after leaving college. Participants all suggested a need to further improve their English proficiency before moving into a long-term career. Participants own self-assessment that they required additional study to improve their English proficiency reinforces this finding. Practitioners are advised to carefully consider whether such a split is taking place within their own programs, and to thoroughly assess the ability of their own curriculum to address this challenge. During this assessment, practitioners are encouraged to reflect on the fact that participants stressed the usefulness of practical ESL classes and each specifically addressed the usefulness of classes teaching oral communication in meeting professional challenges. This may mean requiring remedial courses in four skills ESL classes or altering the curriculum to place a greater emphasis on oral communication.

There is ample room for future research to expand on these findings. First, a broader, qualitative case study may reveal broader trends than this more narrowly focused study. Similar qualitative studies could be preformed in English departments at other private universities and these results contrasted with similar studies done in public universities. Additionally, qualitative and quantitative surveys could be used to better understand participants' feelings on their coursework and program of study and the degree to which these helped them overcome professional challenges.

\subsection{Contribution to the field}

This study has contributed to the ongoing academic dialogue concerning the higher education expansion crisis in Taiwan. In its examination of graduates of an English department in a private Taiwanese university, it has allowed the voices of former students to discuss their preparedness to meet and overcome professional challenges after graduation. Through this presentation, a more complete picture emerges of the challenges students face, how they face them, and their long-term career goals. By encouraging educational leaders to more rigorously track what happens to students after graduation and reflect upon how well their curriculum is preparing students to meet the professional challenges they will face, opportunities and directions for institutional improvement are revealed. 


\section{References}

Boote, D.N. and Beile, P. (2005). Scholars Before Researchers. Educational Researcher, Vol. 34, No. 6, pp. 3-15 Chen, D.S., and Chang, M.K. (2010) Higher Education in Taiwan: The Crisis of Rapid Expansion. Retrieved from http://www.isa-sociology.org/universities-in-crisis/?

Cresswell, J.W. (2009). Research Design: Qualitative, quantitative, and mixed method approaches. Los Angeles. Sage publications.

Cresswell, J.W. (2007). Qualitative inquiry and research design: Choosing among five approaches 2nd edition. Thousand Oaks. Sage publications.

Ministry of Education, Taiwan. (2011). 2009 Educational Statistics Indicators. Retrieved fromhttp:// english.moe.gov.tw/ct.asp?xItem $=10983 \& c t$ Node $=816 \& \mathrm{mp}=11$

Tso, N. (2009) Why Has Taiwan's Birthrate Dropped So Low? Time. Retrieved from http://www.time.com/time/world/article/0,8599,1945937,00.html 